\title{
Monodermal cystic ovarian teratoma composed of respiratory epithelium
}

\author{
S. B. PRASAD \\ B.Sc.(Hons), M.B.B.S., M.S.(Surg), \\ F.C.G.P., M.R.S.H.
}

M. R. SINHA

M.B.B.S., D.G.O., F.C.G.P.

Upgraded Department of Surgery, Darbhanga Medical College, Laheriasarai-846003, Bihar, India and Primary Health Centre, Bahadurpur (Darbhanga), Bihar, India

\begin{abstract}
Summary
An atypical presentation of a mature cystic teratoma of the ovary is presented.

KEY WORDS: ovary, tumour, respiratory epithelium.

\section{Introduction}

Mature cystic teratomas of the ovary composed of tissues derived from a single germ layer (monodermal) are extremely rare. We present a case report of a young girl in whom a cystic ovarian tumour was composed purely of endodermally derived tissue, namely respiratory epithelium.
\end{abstract}

\section{Case report}

A 7-year-old girl reported with a lump in the lower abdomen of 3 months' duration. There was no history of abdominal pain, gastrointestinal or respiratory disturbance, or vaginal discharge.

On examination, there was an intra-abdominal lump situated to the right of midline. The lump was firm and mobile, measuring $10 \mathrm{~cm}$ in diameter. The external genitals were normal. Routine investigations including urine, stool, blood counts, haemoglobin, bleeding and clotting times, plain $\mathrm{X}$-ray of the abdomen and chest and excretory urogram were all within normal limits.

Exploratory laparotomy revealed an enlarged cystic right ovary and a right salpingo-oöphorectomy was carried out. There were some adhesions between the cystic tumour and surrounding pelvic structures. The left ovary, pelvic and other abdominal organs were normal. The postoperative recovery of the patient was uneventful and the patient is alive and well 18 months after.

The removed specimen consisted of a cystic mass measuring $8 \times 5 \times 3 \mathrm{~cm}$. The serosal surface was smooth and white. On cut section, the tumour revealed a multilocular cyst. No solid area was present. The entire tumour was sectioned for histolo- gical evaluations and all sections revealed the simiter histological pictures. The cystic spaces were lined by well differentiated pseudostratified columnar epithe्tium closely resembling normal respiratory epith ium (Fig. 1). The septae were composed of fibroas connective tissue with chronic inflammatory cells. $\mathrm{No}$ other tissues such as neuro-ectodermal tissue, skin, skin appendages and cartilages were found. Occ: sional foci of residual ovarian stroma with primordmal follicles were present subserously in few sections.

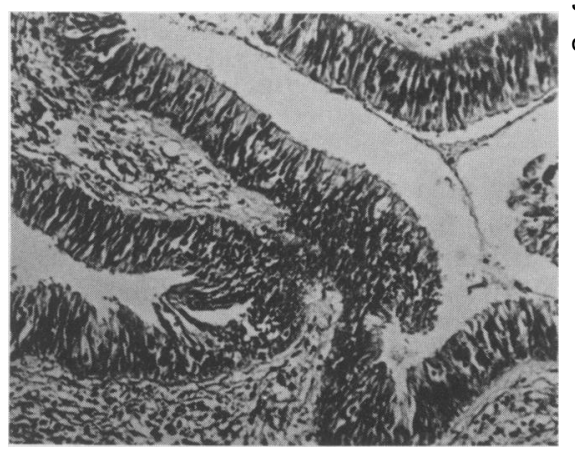

FIG. 1. High power microphotograph of the ovarian tumour showgig pseudostratified columnar epithelium lined spaces (HE. $\times 100$.

\section{Discussion}

The tumour described in the present report is interpreted as a monodermal variant (endodermal) mature cystic teratoma of the ovary, which extremely rare.

Serov, Scully and Sobin (1973) reported $\stackrel{c}{a}^{2}$ subgroup of monodermal and highly specialize्gd teratomas. This subgroup includes stroma ovarin. carcinoids, strumal carcinoids and a miscellaneous category. In addition to the extremely rare sebaceo gland tumour (Strauss and Gates, 1964) and $\Phi_{a}$ 
tumour resembling the retinal analge tumour (Hameed and Burslem, 1970), this miscellaneous category includes the epidermoid cyst, which is lined by mature squamous epithelium. Epidermoid tumours are thought to be mature cystic teratomas derived purely from ectoderm. However, Nogales and Silverberg (1976), in their report of ovarian epidermoid cyst, suggest a possible origin from metaplastic coelomic epithelium.

A similar controversy involves the histogenesis of mucinous tumours of the ovary. While a majority are considered to be of surface epithelial origin, the presence in some tumours of endodermally derived cells, as well as the association with a dermoid cyst in $5 \%$ of cases, raises the possibility that such tumours may be monodermal teratomas (Scully, 1970).

An origin from surface epithelium in the present case is difficult to postulate, as to our knowledge, epithelium of respiratory type has only been reported to occur in the ovary within a teratoma. The present tumour must then be interpreted as a cystic teratoma with one sided development of endoderm manifested purely by respiratory epithelium.

Mature monodermal cystic teratomas reported to date would thus include the ectodermally derived epidermoid cyst, those derived from endoderm (namely some mucinous tumours), the rare case of struma ovarii which is completely cystic (Scully, 1977), and those tumours composed of respiratory epithelium exemplified by the present case as well as that reported by Clement and Dimmick (1979).

It is difficult to make a statement regarding the behaviour of such a tumour; however, it appears to pursue a benign course as exemplified in the present case of brief postoperative follow-up.

\section{Acknowledgments}

We thank Dr S. K. Sarkar, M.S., F.R.C.S., Professor and Head of the Upgraded Department of Surgery, Dr. S.N. Verma, M.Sc., Ph.D.(Manch), Professor and Head of the Pathology Department, Darbhanga Medical College, Laheriasarai (Bihar), India, for their valuable suggestions.

\section{References}

Clement, P.B. \& Dimmick, J.E. (1979) Endometrial variant of mature cystic teratoma of the ovary-report of a case. Cancer, 43 , 383.

HAMEed, K. \& Burslem, M.R.G. (1970) Amelanotic ovarian neoplasm resembling the 'retina analge' tumour. Cancer, 25, 564.

Nogales, F.F. \& SilverberG, S.G. (1976) Epidermoid cysts of the ovary-a report of 5 cases with histogenetic considerations and ultrastructural findings. American Journal of Obstetrics and Gynecology, 124, 523.

SCULLY, R.E. (1970) Recent progress in ovarian cancer. Human Pathology, 1, 73.

SCULlY, R.E. (1977) Ovarian tumours. American Journal of Patho$\log y, 87,686$.

Serov, S.F., SCully, R.E. \& Sobin, L.H. (1973) World Health Organisation Histological Typing of Ovarian Tumours. p. 49 Geneva.

Strauss, A.F. \& Gates, H.S. (1964) Giant sebaceous gland tumour of the ovary. American Journal of Clinical Pathology, 41, 78.

(Accepted 11 June 1982) 